\title{
Into the mediastinum and out of the papilla: minimally invasive endoscopic therapy in two body cavities with one instrument
}

A 48-year-old woman with chronic ethylic pancreatitis presented with new onset of fever, dysphagia, and elevated inflammatory parameters. Computed tomography revealed a large cystic supradiaphragmatic paraesophageal structure and two small retroperitoneal cysts near the pancreatic body. Transesophageal endosonographic fine-needle aspiration showed pus and an elevated amylase level. The diagnosis of an infected pancreatic pseudocyst was made. Consequently, a $10 \mathrm{Fr}$ double-pigtail catheter and a $7 \mathrm{Fr}$ nasocystic tube were inserted transesophageally. Infection was treated with intravenous penicillin according to antimicrobial resistance of the detected Streptococcus anginosus.

During a second intervention 2 weeks later, using a $10 \mathrm{Fr}$ digital endoscope (SpyScope-DS; Boston Scientific, Marlborough, Massachusetts, USA), we were able to locate and pass the transhiatal fistula of the pancreatic pseudocyst after balloon dilation to reach the caudally located smaller part of the pancreatic pseudocyst. After several unsuccessful attempts, a 0.035 inch guidewire was passed under visual guidance through the pancreatic pseudocyst and into the pancreatic duct ( Fig.1, \Video1). The wire was then advanced via the ampulla of Vater into the duodenum and extracted orally. By holding the guidewire tightly at both ends, we were able to support the difficult and precise placement of a $5 \mathrm{Fr}, 13 \mathrm{~cm}$ plastic stent into the pancreatic duct, via the thoracic and abdominal part of the pancreatic pseudocyst. The proximal end was placed visually in the small abdominal cystic part and the distal end was located in the duodenum. The nasocystic tube and double-pigtail catheter were removed and the esophagocystic access was closed using two hemoclips. Subsequently, both the thoracic and the abdominal part of the pancreatic pseudocyst collapsed totally and the patient recovered completely. The stent

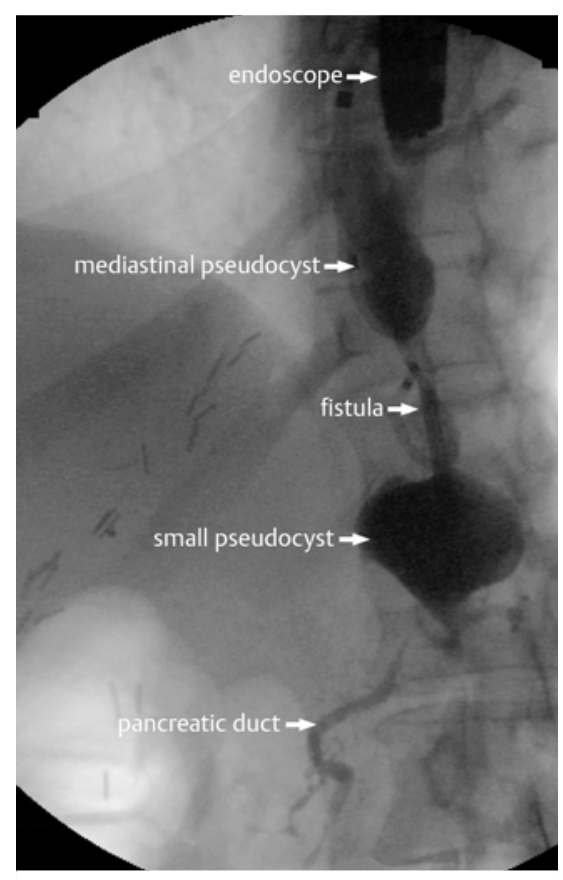

- Fig. 1 Fluoroscopy showing the mediastinal pseudocyst with a caudally located smaller pseudocyst and its connection to the pancreatic duct.

was replaced transpapillarily 3 months later and completely removed 2 months thereafter. The patient continues to be asymptomatic.

Endoscopy_UCTN_Code_TTT_1AS_2AC

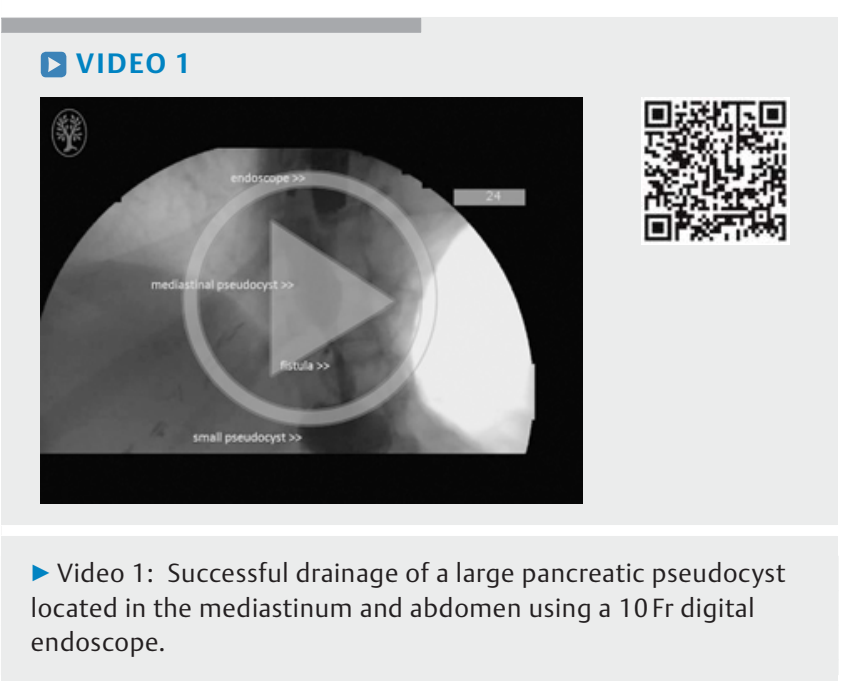

Competing interests

Dr. Magdeburg is a medical consultant for Boston Scientific.

The Authors

Bernhard Magdeburg', Daniela B. Husarik², Thomas Greuter ${ }^{1}$

1 Department of Medicine, GZO - Zurich

Regional Health Center, Wetzikon,

Switzerland

2 Institute of Radiology, GZO - Zurich Regional Health Center, Wetzikon, Switzerland

Corresponding author

Bernhard Magdeburg, MD

Gastroenterology and Hepatology,

GZO - Zurich Regional Health Center, 8610 Wetzikon, Switzerland

Fax: +41-44-9341199

bernhard.magdeburg@gzo.ch

\section{Bibliography}

DOI http://dx.doi.org/10.1055/s-0043-100189 Endoscopy 2017; 49: E81

(c) Georg Thieme Verlag KG

Stuttgart - New York

ISSN 0013-726X 